\title{
Purchasing Strategy Analysis Based on the Relative Value of the Purchasing Material
}

\author{
Xiao-Juan BAI \\ Logistics Institute \\ Beijing Wuzi University \\ Beijing, China \\ E-mail:baixiaojuan@sina.com
}

\author{
Yun-Peng GAO \\ Graduate School \\ Beijing Wuzi University \\ Beijing, China \\ E-mail:gyp931200@sina.com
}

\begin{abstract}
This paper start from the value of materials and the availability of market supply and then put forward the definition of relative value that according to the market availability; Next combined with $\mathrm{C} . \mathrm{V}$ analysis, on the basis of relative value of materials and the stable demand of the companies, the materials seminary matrix is designed; Finally, the purchasing materials positioning model is established, and the purchasing strategy analyses can be provided according to the characteristics of the purchased materials.
\end{abstract}

Keywords-ABC classification, C.V analysis, purchasing strategy

\section{THE INTRODUCTION}

Purchasing management is an important content of enterprise management, which need according to the characteristics of materials that the enterprises purchased to manage the supplier's relationship and analyses the purchasing strategies suitable to reduce procurement costs, guarantee supply stability and improve the overall competitive power of enterprises. In this paper, it based on the characteristics of purchasing materials, considering the value of the material, the difficulty to obtain on the market, the stability of purchasing material requirements in a company and then combined with the research achievements of predecessors to make a further segmentation to the enterprise procurement material. I come up with a purchased material matrix on the relative value of material and study the corresponding purchasing strategy based on this, it is hoped that my research can contribute to a supplier relationship management and purchasing strategy in the theory and practication.

\section{LITERATURE REVIEW}

As the front-end work of supply chain management, procurement plays a fundamental role in the operation of enterprises. Therefore, scholars pay more attention to the research on procurement strategy

In the literature [1], Guohong SHI, Chunlin LI explores the analysis of the purchasing strategy under the supply chain management mode and put forward the following problems should must be considered when we make the procurement strategies: key factors analysis, establish strategic partnership with suppliers, and implement the lean way of inventory management

To the procurement positioning model, Bo JIANG in the literature [2], carry on a thorough discussion, and put forward procurement strategies - procurement projects shift strategy and procurement differentiation strategy which are based on purchasing positioning model. Therefore, he fined a set of convenient and applicable tools for the procurement staff of the enterprise, providing meaningful help for procurement.

In the literature [3], Liguo $\mathrm{ZhNG}$, Runde LU, based on the classification of the importance of purchasing material and the risk of supply, establish the index evaluation system of purchasing model. And then use the analytic hierarchy process (ahp), give the quantitative evaluation model of material purchasing, finally they use $\mathrm{ABC}$ classification model to classify the processing results of the model, which can effectively help enterprises make their purchasing strategy.

Shengchun LIU, Bengang GONG in the literature [4], use the supplier classification matrix to classify the suppliers, and obtain the different management strategy combinations of suppliers. Based on the analysis of the purchasing philosophies and purchasing strategies of supply chain enterprises, the relationship of suppliers is positioned so as to adopt different purchasing management strategies for suppliers of different relationships.

Hui LIU, in the literature [5], according to the difficulties to gain materials, the materials technical requirements, the macro environment, andits own spending ability to get a score, then use the score to multiply by its weight, then gaining a comprehensive value. The higher the value, the greater the risk. She marks the position on spending matrix on the base of the supply risk and cost value of the goods, which can get all supply goods of an enterprise in the location of the expenditure analysis matrix and prepare for purchasing goods classification.

In the literature [6],Fangli WANG, from the point that the purchasing goods and materials that directly related to production, material value, the length of the purchasing cycle, the adaptability of the suppliers, sources of demand, material property, and so on ,to refine the differentiation procurement strategies and the ways of purchasing.

In the literature [7],Hangyi AN, Rui WANG, Min ZHANG, Xiaojun GUO put forward the small companies should join an alliance and expand the scale of procurement and market position from the perspective of electronic procurement in order to solve the problems of scattered and medium-sized purchasing power. In terms of supplier relationship, it is proposed to eliminate the immediate transactions and benefits, take a long-term view and achieving win-win cooperation through cooperation's. 
In the literature [8], Juan XU, Xiaojing WANG, Zhixue LIUin view of the traditional dynamic batch model cannot optimize supplier selection and purchasing batch decision at the same time, treading the suppliers and purchasing period as two state variables, building a two-dimensional planning equation of state variables, and designing a polynomial algorithm to get the optimal purchasing strategies in multi-vendor environment.

Through the analysis, we can see that the research on purchasing strategy is conducted in the following aspects:

- Study procurement based on supply chain, analyze and design the whole purchasing system.

- On the point of materials. Depending on the degree of importance and risk of the, purchasing items classification model and then combined with the $\mathrm{ABC}$ classification to purchase materials to classify to different categories of materials and take a different way to purchase.

- Analyzing the purchasing mode from the perspective of inventory, mainly explore the purchasing strategy under the inventory model, such as supplier management inventory, economic bulk order model, JIT purchasing, etc.

- From the point of products. Basing on the different life cycles of the products to take different purchasing methods and ordering quantity.

Most of these methods focus on the analysis from the point of importing materials, and ignore the use frequencies of materials. This paper from both qualitative and quantitative aspects to analyze. The qualitative aspects are mainly based on $\mathrm{ABC}$ classification and kalajack procurement matrix, which focuses on the analysis of the value of purchasing materials and the complexity of the supply market. Quantitative analysis is to divide the purchasing materials of enterprise by $\mathrm{ABC}$ classification .Combining qualitative and quantitative to form a new positioning about purchase materials, then combine with C.V analysis, point out the stable requirements of the purchasing materials in enterprises, and according to the characteristics of the different materials to provide applicable procurement strategy and fix the suppliers, different supplier relationship management and purchasing strategy analysis on the basis of supplier relationship graph.

\section{THE RELATIVE VALUE OF PURCHASING MATERIALS IN THE COMPANIES}

The relative value of purchasing materials in the Companies is according to the supply situation of materials in the market and combine the value and the availability of materials to make a definition of material value. In this study, the ABC classification and karakjack model were optimized.

According to the historical procurement cost, the procurement materials are divided into three categories. According to the $\mathrm{ABC}$ classification. The materials accounting for about $20 \%$ of the purchase quantity, and worth $80 \%$ are called class $\mathrm{A}$. That the purchase quantity is about $30 \%$, and the $15 \%$ of material value is called class $\mathrm{B}$.while about $50 \%$ of the purchase amount, and the $5 \%$ of material value is called class $\mathrm{C}$.

In Carla jack model, according to the importance of the purchasing materials, the complexity of the supply market to review the purchasing conditions and the risk of supply disruptions of companies, and divided the purchasing materials into non-critical materials, bottle-neck materials, leverage, and strategic materials.

Based on the relative power of the buyer and the supplier in the market, the paper further subdivides the purchasing materials and form the relative value of the purchasing materials. From $\mathrm{A} 1$ to $\mathrm{C} 2$, the organization procurement materials are divided into six categories, representing different value and availability of material characteristics, as follows:

\begin{tabular}{|c|c|c|c|}
\hline & & & \\
\hline Availability & A & B & C \\
\hline poor & A1 & B1 & C1 \\
\hline well & A2 & B2 & C2 \\
\hline
\end{tabular}

Table 1. Material Classification

Class A materials: The value of such materials is high, accounting for $20 \%$ of the total materials amount, the cost accounting for $80 \%$ of the total materials. The materials are composed of A1 and A2 .A1 is scarce, the suppliers are less in the market, the materials are not easy to obtain, and the materials are in the seller's market. A2 is of high value, with more suppliers in the market and easier access to materials in the buyer's market.

Class B materials: These materials are key materials, the number accounts for $30 \%$ of the total materials quantity, and the cost accounts for $15 \%$ of the materials value, although not as good as the kind of $\mathrm{A}$, but for purchasing companies, the value is relatively high, which should not be ignored. It is composed of $\mathrm{B} 1$ and $\mathrm{B} 2$, and the $\mathrm{B} 1$ is difficult to obtain and in sellers' market. There are many sources of supply in the market of B2 materials. The suppliers is greater than the demand. The buyer is in a favorable position in the transaction.

$\mathrm{C}$ materials: the materials value of $\mathrm{C}$ materials is low, the amount of these materials are about $50 \%$ of the total materials, but the amount is only $5 \%$ of the total materials amount. For such materials, the value is low, but also indispensable. These materials are composed of $\mathrm{C} 1$ and $\mathrm{C} 2, \mathrm{C} 1$ materials are of poor availability while the $\mathrm{C} 2$ materials are in the buyer's market. The market is rich and there are many suppliers, which is beneficial to the buyers. It can reduce the cost of procurement process and reduce the cost of purchasing and planning departments in such materials by automating regular bulk purchasing.

\section{THE BREAKDOWN MATRIX OF THE COMPANIES' PROCUREMENT MATERIALS}

\section{A. C.V Analysis}

C.V is called the change coefficient, which describes the fluctuation of materials demand. The calculated value of C.V analysis is the standard deviation of the materials demand divided by the average demand of the materials.

$0.5>$ C.V. This state of affairs indicates that the materials are the most stable part of the whole materials 
inventory. This kind of materials are used very frequently and very stably

$1<\mathrm{C}$.V. This state of affairs illustrates this kind of materials are the most unstable kind of demand, from the point of practical management phenomenon, this kind of materials may have few requirements, Or the amount of demand varies greatly each time.

$0.5<\mathrm{C} . \mathrm{V}<1$. This state of affairs explains the demand characteristics of such materials are between the above classes, not very stable, and they will not present an overly messy dispersion.

The calculation formula is as follows:

$$
\mathrm{C} . \mathrm{V}=\mathrm{SD} / \bar{X}
$$

The standard deviation calculation formula is as follows:

$$
\mathrm{SD}=\sqrt{\frac{1}{N-1} \sum_{i=1}^{N}(X i-\bar{X})^{2}}
$$

$\mathrm{Xi}$ - the number of the I sample;

$\bar{X}$ - The arithmetic mean of sample $\mathrm{X}$;

$\mathrm{N}$ - the number of samples;

\section{B. The Breakdown Matrix of Purchased Materials}

$\mathrm{T}$ content of this part, undertake the relative value of the materials, combined with C.V to make a further analysis, and according to the relative value of materials and materials demand stability of the companies to organize purchasing materials further subdivided, form $3 \mathrm{x}$ 6 subdivision matrix of materials, specific information is in Figure2:

\begin{tabular}{|c|c|c|c|c|c|c|}
\hline $\begin{array}{c}\text { remand } \\
\text { stability }\end{array}$ & A1 & A2 & B1 & B2 & C1 & C2 \\
\hline C.V $<0.5$ & A11 & A21 & B11 & B21 & C11 & C21 \\
\hline $0.5<$ C.V $<1$ & $\mathrm{~A} 12$ & A22 & B12 & B22 & C12 & C22 \\
\hline $1<$ C.V & A13 & A23 & B13 & B23 & C13 & C23 \\
\hline
\end{tabular}

Table 2. The Breakdown Matrix

In this matrix, the materials are divided from A11 class (high value, poor availability, stability) to C23 class (low value, easy to obtain, instability) in detail. According to the above matrix, the companies can be based on the value of the purchased materials, availability, and the stability of the material requirements of a company to describe the materials characteristics. According to purchasing materials positioning model in below, one can find the location of the material in the model, in order to establish the reasonable purchasing strategy based on the characteristics of material classification basis.

\section{PURChASING MATERIAL POSITIONING MODEL AND PURCHASING STRATEGY ANALYSIS}

\section{A. Purchasing Materials Positioning Model}

According to the characteristics of the above materials, the following supply materials positioning model is formed:

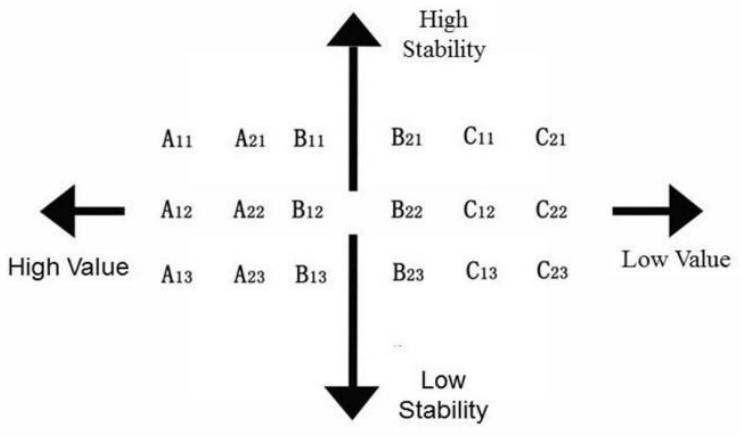

Figure 1. Supply Materials Positioning Model

\section{B. Analysis of Purchasing Strategy}

According to the above model, we can use the position of purchasing materials in the model to determine the material characteristics, and do further analysis. Then we can combined with the supplier relationship model, set up appropriate purchasing strategy and supplier strategy. The analysis of several key material materials is as follows:

A11 type: A11 materials have high value, poor availability, stable material demand, and in sellers' market. Extremely important to the companies. For this kind of material, we should make full use of the suppliers' resources and advantages, and conduct long-term close cooperation with suppliers to form a strategic alliance or partnership to ensure supply safety. In order to improve material quality, share risks and benefits, we can take the strategy of joint development. Due to stable demand and poor availability, it is possible to maintain two or more suppliers for the same materials, and to differentiate between them in order to avoid the supply risk. We can take the order point method in the materials purchasing strategy according to the stable demand. Based on the security inventory plus the requirement of the ordering period, and the economic batch model can be used to purchase.

A13 type: This type of materials has high material value, poor availability and largely change in material requirements. In a company, the demand of this kind of materials change largely. But because the market suppliers are less, not easy to get, we should also establish long-term cooperative relationship with suppliers, such as the exclusive agreement signed with suppliers to create a single source of supply. In a relatively concentrated procurement to increase bargaining power, achieve long-term strategic cooperation and common development, to lower prices in this way. In terms of the contract, the purchaser and the supplier shall conclude the overall framework and submit individual orders as required.

A21 type: This kind of materials has high materials value, good availability and stable materials demand. This kind of materials is in the buyer's market. In the market, the buyers are initiative and can take advantage of the market position to strive for the cooperation clause that is 
advantageous to themselves. Due to high materials value and stable demand, long-term relationship with suppliers should be established to ensure supply and reduce price. Because this kind of materials is expensive, and will take up a lot of money if we put them in Warehouse, so the basic management strategy of material is committed to the total cost minimum, and we should can spend more time in inventory management to reduce inventory as far as possible. With the method of bulk orders, according to the model of economic batch, reduce the purchasing and inventory costs.

A23 type: This kind of materials is of high value, good availability and large demand for materials. Although in the buyer's market, this kind of materials is not often needed. In this case, the purchasers can make use of their advantages, and can establish a close tactical relationship with suppliers. Through the fixed contract or blanket contract with suppliers to establish a relationship of mutual commitment or tread this kind of deal as often happens with suppliers, but is still seen as a supply source, one-time business transactions. The company can identify only one supplier to facilitate the smooth negotiation of the price, and can also use a dual supply source. When one of the supply chains has a problem, the other could take his place. Due to high material value and unstable demand, it is not suitable to store such materials too much. So in terms of inventory, can learn the consignment pattern of Haier, namely the supplier stores the materials in the Haier materials center which is not pay off until the Haier is used. The vendors can check the use of the consignment merchandise through the $\mathrm{B} 2 \mathrm{~B}$ website.

C11 type: This type of materials are low value, poor availability and stable material demand. Although this kind of materials are low value, the materials demand is large, and the market suppliers is short, companies should be given a certain value, puts focus on security of supply in order to prevent the risk of out of stock. So buyers and suppliers should still establish long-term or medium-term partnerships to ensure supply and cost advantage. Or use dual supply source searching to ensure continuity of quality and supply. In terms of purchasing and inventory strategy, it is possible to consider setting up high inventory and adopt the largest order to reduce transaction costs as a result of low value and stable demand.

C13 type: The value of $\mathrm{C} 13$ materials is low, the availability is poor, and the demand for materials changes greatly. The requirements of this type of materials change greatly, poor availability, less suppliers on the market. So the companies should establish long-term relations with suppliers, adopt double supply source strategy, or the method of large order, reduce transaction costs. Maintain good communication with suppliers, improve supply reliability or improve materials design, and find substitutes

C21 type: This type of materials are low value, good availability and stable material demand. This kind of materials exist lots of suppliers in the market. Because of the needs is stable, so we can use loose even antagonistic relations, to strive for benefit maximization. It's not worth to pay much to build up close relationship, and automated procurement can be adopted to reduce procurement costs as much as possible.
C23 type: This kind of materials is of low value, good availability and great changes in materials requirements. Because of low value, good availability, we can tread this type of materials with the method of the large order and it's not worth to pay to build up close relationship, there are lots of the market suppliers, so we can take the opposite relationship to maximize their own interests.

The above several types of materials have obvious characteristics in the materials value, the market supply situation, and the stability of company's needs. For other materials, such as the A22, B12, etc., the difference in characteristics with above-mentioned materials is not obvious. In this case, the shift strategy can be used in the intermediate matrix to increase the characteristics of the material in one aspect through the adjustment of the procurement mode. For example the $\mathrm{C} 12$ materials, these type of materials is in low value and can obtain poor quality. The companies have relatively stable demand for materials. Although this kind of materials value is low, but because of poor availability, procurement is still at a disadvantage condition. At this moment, we can look for alternative ways, explore potential suppliers, in order to increase the market supply, and turn $\mathrm{C} 12$ products into $\mathrm{C} 21$ products to change the market position and increase bargaining power.

\section{THE CONCLUSION}

The procurement activities of a companies should according to purchasing materials subdivision positioning to determine the specific procurement methods and suppliers management strategies. Both to consider the value of materials and the transaction and inventory cost. Finding the balance between cost control and risk prevention to specify supplier positioning and guarantee the quality and continuity of material supply, then to improve the level of company's procurement.

\section{ACKNOWLEDGMENT}

Papers published by the BEIJING SOCIAL SCIENCE FUND RESEARCH BASE PROJECT funded. (Project number 14JDJGB038)

\section{REFERENCE}

[1] Guohong SHI, Chunlin LI ,Analysis and research of purchasing strategy in supply chain model[J],Journal of Jiangsu University,2005,4:85-87

[2] Bo JIANG ,Procurement strategy and its implementation analysis based on purchasing location model[J],Logistics technology,2009,28(10):61-64

[3] LiGuo ZHANG,Runde LU ,Enterprise purchase model based on Analytic Hierarchy Process[J],Journal of Guilin University of Electronic Technology,2006,26(4):290-293

[4] Shengchun LIU , Study on purchasing strategy of supply chain enterprises based on supplier relationship[J],Technology and Industry2012,9(9);122-126

[5] hui LIU, Optimization of enterprise materials classification and purchasing strategy $[\mathrm{J}]$, logistics engineering and management,2009,31(1): 67-69

[6] Fangli WANG, Making fine and differentiated purchasing strategies and purchasing methods, www.pmweb.com.cn, 2015.9

[7] Hangyi AN, RuiWang, Minzhang, Xiaojun Guo ,Study on Problems and Countermeasures of electronic purchasing management [J] Journal of Southwest Petroleum University,2013, 15(3): $24-30$ 
[8] Juan XU, Xiaojing WANG, Zhixue LIU ,Optimal purchasing strategy in multi suppliers environment [J] Journal of Southwest Petroleum University, 2014,23 (6): 24-29

[9] CIPS STUDY MATTERS, Contract relationship management in purchasing and supply chain $[\mathrm{M}]$, Beijing Sino logistics human resources training center, Beijing: China Machine Press, 2014.6:1-55.

[10] Huang FANG, supplier selection and relationship management, [D], Nanjing, Nanjing University of Science and Technology, 2008:1-48

[11] Gao JIN, [D], Material purchasing strategy based on the subdivision of Shanghai, Shanghai Jiao Tong University, 2008:1-54

[12] Fuzong GONG, research on purchasing strategy of W company based on supply positioning model [D], Shanghai, Shanghai International Studies University, 2013:1-50 